Revue d'histoire de l'Amérique française

REYUE D.HISTOIRE DE L'AMÉRIQUE FRANÇAISE

\title{
Présentation du volume 40 de la RHAF
}

\section{Richard Jones}

Volume 40, numéro 1, été 1986

URI : https://id.erudit.org/iderudit/304421ar

DOI : https://doi.org/10.7202/304421ar

Aller au sommaire du numéro

Éditeur(s)

Institut d'histoire de l'Amérique française

ISSN

0035-2357 (imprimé)

1492-1383 (numérique)

Découvrir la revue

Citer ce document

Jones, R. (1986). Présentation du volume 40 de la RHAF. Revue d'histoire de l'Amérique française, 40(1), 3-3. https://doi.org/10.7202/304421ar d'utilisation que vous pouvez consulter en ligne.

https://apropos.erudit.org/fr/usagers/politique-dutilisation/ 


\section{PRÉSENTATION DU VOLUME 40 DE LA RHAF}

L'année 1986-1987 marque le quarantième anniversaire de fondation de la Revue d'histoire de l'Amérique française. Bien sûr, nous nous réjouissons de ce long passé. Par contre, puisqu'on dit que la vie débute à quarante ans, nous pouvons en même temps avoir confiance en l'avenir!

Les activités entourant cette fête seront forcément modestes. Nous souhaitons entre autres publier un quatrième index décennal dans le but de faciliter les recherches de nos lecteurs. Afin d'en financer la confection et la puölication, le directeur scientifique et le trésorier ont déposé auprès du Conseil de recherches en sciences humaines du Canada une demande de subvention. Nous espérons vivement faire paraître cet index hors série pour ne pas priver nos abonnés d'un numéro régulier. Toutefois, nos lecteurs, peut-être trop habitués aux discours électoraux, ne devront pas considérer ce simple voeu comme une promesse!

Par ailleurs, un bref résumé (environ 150 mots), en français et en anglais, accompagnera désormais les articles et les notes de recherche. Cette politique, suivie par un grand nombre de revues surtout européennes, devra faciliter la consultation de la Revue. A cette fin, nos auteurs éventuels devront joindre à leur texte les résumés.

RICHARD JONES

Directeur 